\title{
Multidimensional Child Poverty from the Child Rights-Based Approach: A Latent Class Analysis to Estimating Child Poverty Groups in Mexico
}

\author{
Yedith B. Guillén-Fernández ${ }^{1}\left[\begin{array}{l}{[0} \\ \text { D Delfino Vargas-Chanes }\end{array}{ }^{1}\right.$
}

Accepted: 6 July 2021 / Published online: 28 July 2021

(C) The Author(s), under exclusive licence to Springer Nature B.V. 2021

\begin{abstract}
The study aims at estimating multidimensional poverty groups among children under five years of age in Mexico. Our analysis is based upon the framework on the Rights of the Child. For this purpose, we focus on identifying different types of child deprivation and the various risk factors that determine child poverty in Mexico, such as the type of locality, ethnicity and the region of Mexico where children live, among others. The study is based on the theoretical notion that children must realize their specific rights, established in the Mexican legal framework, in order to achieve an adequate standard of living and guarantee the well-being and development of children. For this reason, child development has been included as one of the analytical dimensions of poverty, because this has been often discarded in child poverty studies. We support the idea that any violation of social rights means deprivation. The method applied in this research is a conditional latent class analysis and we use covariates which have helped for better predicting the average probabilities of experiencing deprivations in each latent class. Thus, the main objective of the study is to identify groups of children experiencing extreme, moderate and no poverty. The results show that children under five years in Mexico, belonging to the poorest stratum have represented about twenty percent; however, fifty percent of them have experienced moderate poverty and only thirty percent are non-poor. We conclude that universal and targeted policies should be implemented to eradicate multidimensional child poverty.
\end{abstract}

Keywords Multidimensional Child Poverty (MCP) · Deprivations · Children's rights $\cdot$ Child development $\cdot$ Latent class analysis (LCA)

Yedith B. Guillén-Fernández yedith@comunidad.unam.mx

1 Universidad Nacional Autónoma de México (UNAM), Programa Universitario de Estudios del Desarrollo (PUED), Mexico City, Mexico 


\section{Introduction}

In Mexico, about a half of children in early age are multidimensional poor, according to official figures. The poverty incidence of children aged under five years was $52 \%$ in 2018. Although, the incidence of child deprivation was even higher, $76 \%$ of them experienced social deprivations. ${ }^{1}$ Moreover, the Mexican children of all ages (0-17 years old) are the poorest age group compared to the economic active population, aged 18 to 64 years and the elderly people aged 65 years and more. The last-mentioned groups showed a high incidence of deprivations, of 71 and 68\%, but slightly lower than the child and adolescent groups (CONEVAL, 2020). These situations reveal that the social rights of children have been systematically breached in Mexico. Children represent a key population group, because their vulnerability to poverty and the condition of poverty per se may persist to the adulthood and can be transmitted through generations (Wagmiller \& Adelman, 2009).

We conceive 'multidimensional poverty' as all kinds of deprivations and conditions that infringe the human rights (Speth, 1998), which also represent the violation of the children's rights (UNGA, 2006). Furthermore, multidimensional poverty encompasses several kinds of social, cultural and environmental limitations that prevent children from achieving their development, such as for example, illness, inadequate nutrition, lack of time for recreation, lack of information and domestic violence (Tuñón et al., 2015), implying the non-realization of their adequate mental, emotional or physical wellbeing (Ben-Arieh et al, 2014). The United Nations have defined poverty as the set of deprivations regarding nutrition, water, and sanitation facilities, access to basic health-care services, shelter, education, participation and protection, leaving children unable to enjoy their rights, reach their full potential and participate as full members of the society (UNGA, 2006).

Why is it important to estimate accurately the measurement of multidimensional child poverty (MCP)? The importance lies in the possibility of designing and implementing comprehensive social policies, based on the children's rights, but also of targeting the poorest children with specific policies. However, we also need to consider different factors as poverty is not only multidimensional but multifactorial as well. It means that there are diverse predictors determining $\mathrm{MCP}$, such as for example, rurality, socioeconomic regions, low educational attainment of the head of households and ethnicity, among others.

In Mexico, social rights represent the social consensus of the population since the Constitution was enacted in 1917. However, the Constitution have had several amendments due to new social rights that have been recognized by the society itself and implemented through processes of democracy. Furthermore, the international covenants of social rights have been endorsed by Mexicans at the level of their Constitution (DOF, 1917, reformed in 2011). This recognition also includes the basic

\footnotetext{
1 The National Council for the Evaluation of Social Development Policy (CONEVAL) measures multidimensional poverty in official terms in Mexico. And they also estimate the index of social deprivation when people experience at least one social deprivation (CONEVAL, 2019).
} 
rights of children that have been established in the 1989 Convention on the Rights of the Child, which was ratified by Mexico in 1990 (UN, 1990).

The Convention has established a minimum floor of rights that every State should guarantee to every child (UN, 1990). On this basis, UNICEF have advocated the definition of "overall poverty" and measures multidimensional child poverty based on the basic rights of children ${ }^{3}$ (Gordon et al, 2003).

Nevertheless, a minimum floor of rights ${ }^{4}$ and standards 5 are not entirely applicable for the measurement of MCP and deprivation in Mexico. The reason is that social and economic progress should be also considered (Townsend, 1979) and the Mexican General Law of Social Development (LGDS by its acronym in Spanish), enacted in 2004 also established that every person must participate from the benefits of social development (DOF, 2004). This also means that new rights are embodied in the Mexican laws, such as the right to access to information, i.e. internet or other sources of information. So, new rights and standards should be taken into account in any methodology of MCP.

In Mexico there are various legal frameworks that mandate the realization of the children's rights. The Mexican Constitution is the norm with the highest rank within the Mexican legal framework. The Constitution establishes that every person is entitled to the rights defined in the law as well as in the international treaties, ratified by the State. Also, the General Law for girls, boys and adolescents (LGNNA, by its acronym in Spanish), enacted in 2014, has established "the best interests of childhood", which means that the State must fully guarantee the entitlements of children (DOF, 2014). The child rights are also governed by the principle of progressivity. This means that there is no setback in the processes of the implementation of policies to accomplish the children's rights, but also a maximum use of resources should be available (Serrano \& Vázquez, 2013).

We aim at conceptualizing child poverty based on the comprehensive list of the social rights of children defined in the Mexican law. We construct an integrative definition of MCP by also considering all those conditions that prevent children from performing well and healthy in their daily activities, plus those deprivations that restrict their levels of well-being and development.

The United Nations Economic Commission for Europe has published the document entitled "Poverty Measurement: Guide to Data Disaggregation", which has been formally endorsed by the Conference of European Statisticians and their Recommendation 29 states the following:

\footnotetext{
2 The concept of "overall poverty" was defined by considering not only income, but also different aspects related to living standards, lack of social participation, discrimination and exclusion, between others (UN, 1995).

3 UNICEF adopted the Bristol and London's methodology of child poverty in the "State of the Children" reports (Gordon et al, 2003).

4 We called the term "minimum floor of rights" when referring to a restricted set of social rights, and it is by no means the entire set of social rights that children are entitled in Mexico.

5 The standards of rights defined in the Constitution become poverty thresholds at the time to measure deprivations in this study. For example, high school is the mandatory educational attainment that every citizen in Mexico should realize by law (DOF, 1917, reformed in 2012).
} 
Countries should use available datasets, such as Multiple Indicator Cluster Surveys (MICS) or household surveys to develop child-specific and life-cycle adapted multidimensional poverty measures that reflect the needs of children at different stages of development... (UNECE, 2020, p. 201).

This recommendation can also be applied to Mexico. Thus, our study proposes five core things to estimate MCP:

Firstly, we include a comprehensive definition of MCP by incorporating the dimension of 'child development' and by recognizing that children have 'specific rights'. An important poverty dimension is child development because is an area of child wellbeing (Save the Children, 2008). Secondly, we construct a latent concept of MCP with seven different poverty dimensions and sociodemographic determinants. Thirdly, we estimate a conditional latent class analysis to obtain stratified groups of MCP. Fourth, we estimate the odds ratios of experiencing multiple deprivations according to socioeconomic determinants, which are incorporated as covariates in the model and influence child poverty. Finally, our ultimate goal is to establish a link between the measurement of MCP and social policies.

\section{Human-Rights and Multidimensional Poverty Measurement in Mexico}

There are different laws and norms that recognize the human rights that every person is entitled in Mexico; but also, there are specific norms that define the rights of the children.

The Mexican Constitution establishes the following mandate concerning the rights of people: "In the United Mexican States all people will enjoy human rights recognized in this Constitution and in the international treaties of which the Mexican State is party, as well as the guarantees for their protection (DOF, 1917, reformed 2011). Article 1 mandates that international treaties are complied with the same level of obligation as the Mexican Constitution. This means that the international framework of child rights, i.e. the United Nations Convention on the Rights of the Child (UNCRC) should be also accomplished (UN, 1990).

Also, the United Nations (UN) has acknowledged that child poverty and deprivation mean a violation of children's rights when children lack the basic needs and services for the guarantee of their rights:

...children living in poverty are deprived of nutrition, water and sanitation facilities, access to basic health-care services, shelter, education, participation and protection, and that while a severe lack of goods and services hurts every human being, it is most threatening and harmful to children, leaving them unable to enjoy their rights, to reach their full potential and to participate as full members of society (UNGA, 2006: p. 46).

In Mexico, the 2004 LGDS established for the first time the mandate to guarantee the full exercise of social rights and to ensure access for all population to social development (DOF, 2004). The LGDS represents a breakthrough because 
it gives basis to identify multidimensional poverty through a social rights-based approach. The National Council for the Evaluation of Social Development Policy ${ }^{6}$ (CONEVAL, by its acronym in Spanish) was created from the establishment of the LGDS law. So, CONEVAL (2019) has the purpose to estimate the Methodology for Multidimensional Poverty Measurement (MMPM) in official terms since 2008.

Additionally, the MMPM has pragmatically represented the society's consensus because it involves democratic processes based on the will of the people, approved in the Congress of the Mexican Union, and finally enacted in the LGDS law. These processes also imply the recognition of the State to ensure the accomplishment of social rights for every person in Mexico; so the measurement of poverty and the design and implementation of the social development policy should be oriented to comply with the mandate of the law (Cuesta et al, 2020).

CONEVAL defines multidimensional poverty as follows:

A person is considered to be multidimensional poor when the exercise of at least one of her social rights is not guaranteed and if she also has an income that is insufficient to buy the goods and services required to fully satisfy her needs (CONEVAL, 2010, p. 28).

One of the properties of the CONEVAL's (2010) poverty measure is its aggregation. The method is arithmetic and aims to sum up the wellbeing and human rights dimensions for the analysis of multidimensional poverty. However, our criticism to this methodology is that their criteria do not identify deprivations based on individual children's information, or deprivations aiming at representing the denial of the rights of children. Moreover, there is no comprehensive national data information addressing the children's needs to measure MCP periodically.

\section{Defining Multidimensional Child Poverty from the Child Rights Framework}

We advocate Townsend's (2008) approach to show that children have specific social rights and needs, which should be accomplished to achieve their wellbeing and development. Townsend (1979) devised that poverty is relative in time and space and stated that poverty should be measured based on the prevailing living standards in each society. Gordon and Nandy (2012) argue that poverty measurement applied to a specific country should consider their social and cultural context, as well as children's needs as they grow and develop.

We aim to estimate MCP through indicators of children's living standards, which capture directly the living conditions of the Mexican children. The estimation of MCP in this study is based on the indicators that reveal multiple deprivations in childhood, which harm children's wellbeing and development.

UNICEF (2010) states that adult poverty should be distinguished of child poverty:

\footnotetext{
${ }^{6}$ CONEVAL in Spanish is the Consejo Nacional de Evaluación de la Política de Desarrollo Social.
} 
The concept of child poverty must be analyzed outside of the traditional parameters for measuring poverty - like low income or household consumption- because some aspects of child poverty go undetected by these measurements: insecurity, lack of freedom caused by harassment or abuse and social exclusion. The impact of poverty on children and adolescents, and the way they experience it, must be taken into account, because they do not benefit to the same extent from the income or consumption of the household in which they live. For them, poverty is a profound experience that involves human relations and that is manifested in a relative as well as in a dynamic and multidimensional manner (UNICEF, 2010, p. 10).

So, we have included the dimension of child development in the definition and measure of MCP. Because child development includes cognitive, physical and psychological domains that are strongly related to poverty, including their environment. These several settings in which a child is directly involved influence their development (Bronfenbrenner, 1981; Garbarino, 2014). Child development is paramount in early childhood. For example, children's language development begins before they speak their first word and is a complex process related to other processes, such as attention, memory, language, and motivation (Berlinski \& Schady, 2015). Also, Duncan and Brooks-Gun (2003) state that persistent poverty affects adversely in early childhood by hindering children's abilities and their educational achievement. These authors suggest that policies should avoid economic deprivation and its effects on childhood.

Child poverty means also that children cannot accomplish a healthy life, develop intellectual skills, have adequate physical and emotional conditions, between other aspects: The State of the World's Children 2005 affirms that 'child poverty' implies deprivations that have been identified as the lack of material, spiritual and emotional resources, necessary for children to survive, develop, and flourish; which prevents them from enjoying their rights, achieving their full potential to participate as full members of society (UNICEF, 2004).

Additional studies have included other child poverty dimensions. In Argentina, MCP has been studied considering deprivations due to deficiencies in stimulation and by taking into account indicators concerning to reading stories, playing with children, attending educational centers and physical or verbal abuse, among others (Tuñón et al. 2015). Biggeri et al (2010) add care, autonomy and social inclusion.

Currently, there are advances in the understanding of poverty as a multidimensional problem, particularly from the social-rights based approach, in which the relational character of child poverty is also considered, i.e. several actors are involved such as the causes of poverty as well as the assessment of impacts of governmental action on the communities experiencing poverty, since the social rights framework renders obligations to the State Parties (Donald \& Mottershaw, 2009; Espíndola et al., 2017).

Mexico has advocated a comprehensive human rights framework for the measurement of poverty but needs to transit to reliable and valid measure of MCP, based on 'child-specific indicators'. UNICEF has mentioned that the inclusion of child-specific needs can improve the measurement of child poverty (UNECE, 
Table 1 List of children's rights in Mexico established in the LGDNNA

List of children's rights

The LGNNA defines the following children's rights

I. Right to life, peace, survival and development

II. Right of priority

III. Right to identity

IV. Right to live in a family

V. Right to substantive equality

VI. Right not to be discriminated

VII. Right to live in well-being conditions and enjoy a healthy and integral development

VIII. Right to a life free of violence and personal integrity

IX. Right to health protection and social security

$\mathrm{X}$. Right to the inclusion of children and adolescents with disabilities

XI. Right to Education

XII. Right to rest and recreation

XIII. Right to freedom regarding ethical convictions, thought, conscience, religion and culture

XIV. Right to freedom of expression and access to information

XV. Right of participation

XVI. Right of association and assembly

XVII. Right to privacy

XVIII. Right to legal certainty and due process

XIX. Right of being migrant children and adolescents

$\mathrm{XX}$. Right to access to Information and Communications Technology

Source Own elaboration based on the LGDNNA (DOF, 2014).

2020). There is a progress in normative terms in Mexico, as the LGDNNA was enacted to accomplish the rights of children and guarantee their care and integral development (DOF, 2014).

From these points of view, we define child poverty as the lack of adequate living standards that prevent children from living decently and realizing their physical, social, cultural, psychological, emotional and mental development; aspects that are also related with children's wellbeing and health. All conditions and circumstances that prevent children from achieving decent standards of living that are related to their social and human rights, we define them as deprivations, which in terms of the social rights-based approach are seen as violations of the rights of children. All those deprivations and conditions that threaten children's wellbeing and child development mean poverty.

We have identified the child rights based upon the LGDNNA (Table 1). This law establishes in its Article 15 that girls, boys and adolescents should enjoy a life in accordance with their dignity and their integral development through the accomplishment of the following rights: 


\section{Data and Methods}

We have carried out this study based upon secondary data analysis and our approach is quantitative. The data used in this study come from the UNICEF's Multiple Indicator Cluster Surveys (MICS) in order to estimate groups of MCP in Mexico. The 2015 MICS is the first survey carried out in Mexico focused on child wellbeing. It is worth noting that the MICS survey has been used by scholars to present research studies related to child deprivation and malnutrition, for example, Pomati and Nandy (2019) show evidence of the prevalence of multiple anthropometric failures for children under five from West and Central Africa. Also, Biggeri and Cuesta (2021) explain that there is a wide range of domains included in the MICS survey that are systematically collected, related to domestic violence, health, sanitation, life satisfaction, discrimination, etc. Additionally, the scholars also indicate that the new round of MICS detects whether the drinking water of the household is contaminated, so that there are domains at the individual and household level that will be taken into account in this study, to estimate MCP for the Mexican children.

We use the 2015 Mexican MICS survey carried out by UNICEF and the National Institute of Public Health of Mexico (INSP). ${ }^{7}$ UNICEF and INSP called the Mexican survey "Encuesta Nacional de los Niños, Niñas y Mujeres en México" (ENIM), however, the survey was designed and developed based on the MICS theoretical framework and includes the same variables of the general MICS data surveys. The Mexican 2015 data survey is representative for children and mothers or principal carers who were interviewed at the time of the survey. Data are also representative for five regions of Mexico, these are: Northwest, Northeast, Center, Mexico City and the State of Mexico, as well as the South of the country (INSP \& UNICEF, 2016). The MICS surveys are also based on data collected at community, household, and individual level, and are representative both nationally and sub-nationally, by regions and type of localities (Pomati \& Nandy, 2019).

MICS surveys consist of a probabilistic and stratified sample design, and the selection at each stage is strictly random. The 2015 Mexican MICS survey contains 8,216 eligible children aged under five years and 8,066 women or tutors who were interviewed and are our target population in this study. The response rate was of 98.2 per cent. There are 2,948 indigenous children, who represent $37 \%$ of the sample. The information provided by the respondents is anonymous. ${ }^{8}$ The survey includes different domains to analyze the children and women's wellbeing, which are: (a) Water and Sanitation; (b) Children's health; (c) Functioning and disability; (d) Child Development; (e) Nutrition; (f) Literacy and Education; (g) Aids and sexual behavior; (h) Subjective well-being and depressive symptomatology; i) Child protection; (j) Reproductive health; (k) Access to the media and use of information/communication technologies (INSP \& UNICEF, 2016). For this study, we have considered the survey domains that are related to our theoretical definition of MCP.

\footnotetext{
7 The INSP is called the Instituto Nacional de Salud Pública, in Spanish.

${ }^{8}$ The data survey can be downloaded from the following website: https://mics.unicef.org/surveys.
} 
The method applied in this study is a conditional latent class analysis (LCA), in order to obtain latent groups of children living in poverty. The conditional LCA uses covariates to predict probabilities of experiencing multiple deprivations for each latent class. We argue that covariates help us classify groups of children living in extreme, moderate and non-poverty.

We use the Bayes formula to estimate the posterior probabilities of class, which indicate the probability of a specific observation that is classified in a given class and is expressed as follows (Wang \& Wang, 2012, p. 291):

Formula 1:

$$
P\left(C=k \mid x_{1}, x_{2}, \ldots x_{Q}=\frac{P(C=k) P\left(x_{1} \mid C=k\right) P\left(x_{2} \mid C=k\right) \ldots P\left(x_{Q} \mid C=k\right)}{P\left(x_{1}, x_{2}, x_{Q}\right)}\right.
$$

The conditional probabilities are those associated with the latent classes (shown in the left side of the Formula 1) and the average of these probabilities is equivalent to the relative frequency of belonging to each class. Thus, a conditional probability close to unity indicates the probability of belonging to a specific class and a probability close to 0 indicates not belonging to that class. To calculate the probability of class membership can be defined as follows:

Formula 2:

$$
P\left(x_{q}=x_{q j} \mid C=k\right)=\frac{1}{1+\exp \left(-L_{j k}\right)^{\prime}}
$$

where $x_{q}$ takes a particular $j$-th value equal to $x_{q j}$ and $q=1,2, \ldots, Q$.

\subsection{Data Analysis}

Statistical analysis was performed using STATA version 16 for calculating the variables and covariates, and to carry out descriptive analysis. We also use Mplus version 8 to estimate the LCA model.

The data analysis involves a two-step process. Firstly, we present the section of 'the extent of multiple deprivations in childhood', where we test the differences regarding the incidence of deprivations by sociodemographic groups. We test whether these differences are significant using Pearson's chi-square test. This test is used to analyze whether different populations are similar (homogenous or equal) in terms of specific characteristics (Bolboacă et al., 2011). Some of the sociodemographic groups that have been compared are for instance, children living in rural areas versus urban areas; indigenous and non-indigenous children, between others.

Secondly, we have estimated a conditional LCA to classify MCP in different groups. So, we rely on a Latent Structure Model, where MCP is the latent dependent variable and is composed of a set of poverty dimensions. We pose in our study that the MCP concept can be inferred statistically through the measure of observed variables. The LCA constructs latent classes within which there is no longer any association of one deprivation with another, the multiple deprivations will be 
"conditionally independent", i.e., conditional on class membership (Henry, 2014; Vermunt \& Magidson, 2020).

MCP is defined as the denial of the rights of children (deprivations). Table 1 shows the list of children's rights from the LGDNNA, which have been considered for our analysis, and we have selected the following because of data availability: a) The right to live in well-being conditions and enjoy a healthy and integral development; b) The right to health protection and social security; c) The right to education; d) The right to rest and recreation and e) The right to access to Information and Communications Technology. Table 2 shows the latent structure model composed by seven poverty dimensions, which were classified based on the aforementioned child rights and based on our poverty definition. The poverty dimensions are Information, Durables, Services in the dwelling and Sanitation, which provide information at the household level. And Healthcare, Nutrition and Child Development include childspecific indicators. These poverty dimensions are integrated by the observed variables provided by the MICS survey, such as internet, computer and TV at home, etc., but these also are encompassed in the rights defined in the LGDNNA children's law.

The data analysis includes the construction of observed variables and covariates that helped estimate the LCA model. We use covariates for the analysis, with the purpose to give account of sociodemographic determinants and to better predict the groups of poverty in childhood. The latent class analysis and the selection of the best-fit model are explained below.

\subsection{Variables and Covariates}

The variables used in this study refer to the multiple deprivations that children have suffered in the Mexican context in 2015. The deprivations were calculated as dichotomous variables; where 0 indicates that the child does not experience $x$ deprivation, and the code 1 denotes a situation in which the child does experience $x$ deprivation. Most of the variables were calculated with the direct response of the interviewees to know whether or not they had access to different items or public services.

The indicators chosen at the household level were identified from those used in the official poverty methodology (MMPM), such as the use of fuel for cooking, overcrowding and roofing materials, ${ }^{9}$ which are related to the poverty dimension of services in the dwelling. The variable of overcrowding was constructed based on the CONEVAL's (2019) poverty method, through considering the ratio of people per room in the dwelling, i.e. when it is greater than 2.5 , then, there is deprivation. Also, the variable of roofing materials was calculated, this indicates deprivation if the roof of the dwelling is made of cardboard sheets or waste. And deprivation in access to fuel indicates that there is no electricity at home and no gas for cooking, or when firewood or charcoal are used for cooking inside the dwelling.

Besides, the dimension of access to durables in the dwelling includes the use of vehicles, the access to a stove, fridge, washing machine, etc. (Table 2). Additionally,

\footnotetext{
9 Walls materials and flooring materials were also considered; however, these variables were not significant in the model.
} 


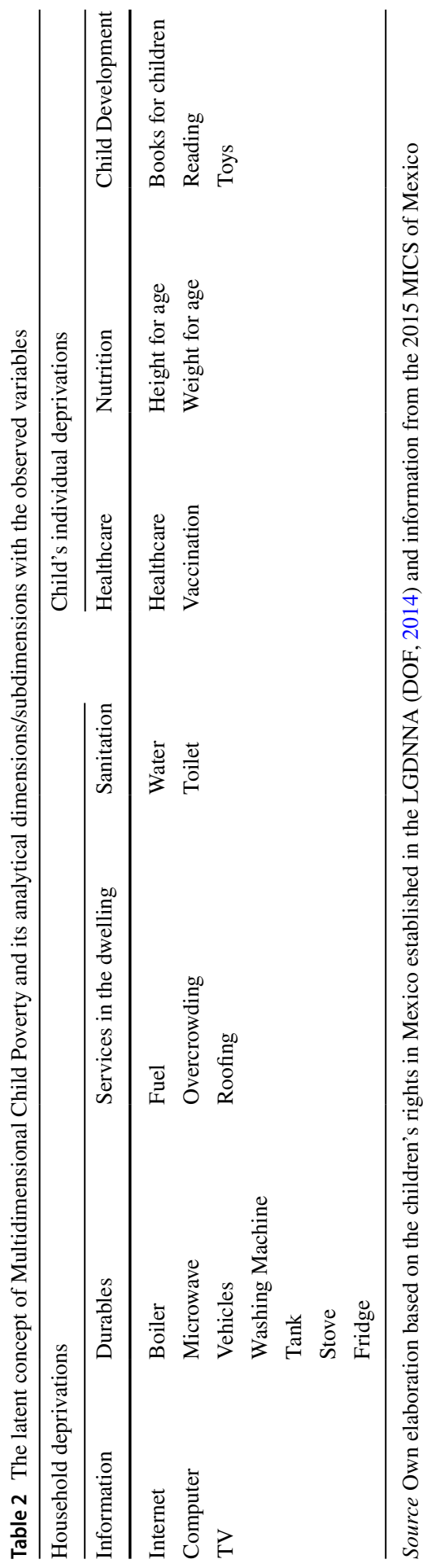


the dimension of sanitation is composed by indicators of the access to toilet and water in the dwelling. We also considered other variables, such as the availability of soap for washing hands at home, but it was no significant.

The dimension of information is composed by the indicators of the access to internet at home; access to computer or laptop; and access either to TV or TV contract (Table 2). These indicators are also included on the basis of the Mexican legal framework, which establishes the right to information for $\operatorname{children}^{10}$ (DOF, 2014).

Child-specific indicators are also shown by poverty dimensions in Table 2. Healthcare is composed of indicators that not only show children's access to a healthcare system; we also consider vaccinations in childhood. This variable was calculated through identifying whether or not children have been vaccinated of either measles or mumps. Other vaccines were used to calculate vaccination, such as influenza and others; however, these other vaccines were not significant in the model. $^{11}$

Besides, child nutrition is composed of indicators of height for age (stunting) ${ }^{12}$ and weight for age, which were calculated by using minus two standard deviations (-2 sd.), to show that children have experienced undernutrition; however, these variables were significant in the model by using -1 sd. Weight for height was also estimated but it was not significant.

Additionally, we have proposed in this study the dimension of Child Development for its inclusion to MCP. Our indicators for this analytical dimension are the access to books for children ( 2 or more) at home; parents that spend time to read a book for their child; availability of toys at home and children spending time playing with their parents as well.

The covariates used to predict the LCA model are also dichotomous indicators, and are mentioned as follows: (a) the type of locality: rural or urban; (b) the region of the country where the child lives: South and Central-North Mexico; (c) the fathers' educational attainment, in this case, deprivation refers to the person that has not achieved the mandatory education established in the Constitution (high school), and non-deprivation is denoted by those who have achieved high school; (d) the mother's educational attainment, estimated as mentioned above; (e) the ethnicity of the children: indigenous and non-indigenous children; (f) the age of children: 0-2 and 3-5 years old; (g) the mother's age, one of the categories is women aged less than 18 years old and the other category is 18 years or more.

\footnotetext{
10 Art. 101 Bis 2 of the LGDNNA establishes that "Girls, boys and adolescents have the right to safe access and use of the Internet as an effective means to exercise the rights to information, communication, education, health, recreation, non-discrimination, among others..." (DOF, 2014, p. 40).

11 We tried also a more complex variable including all vaccines, but it was not significant.

12 Children are defined as stunted if their height-for-age is more than two standard deviations below the WHO Child Growth Standards median (WHO, 2010).
} 


\subsection{Latent Class Analysis}

The LCA analysis estimated the poorest and moderate strata of poverty, according to the multiple deprivations already described previously, as well as the group of non-poor children. LCA comprises the following analysis steps: Firstly, the statistical criteria are shown to select the model with the best goodness of fit, in order to identify the number of latent classes. We obtained subsequently, the average probabilities of experiencing multiple deprivations for each latent class, with the purpose to guide the design and implementation of social policy (Schotte et al, 2018). Thirdly, the incidence of poverty is presented for each poverty group. Finally, the model reveals the odds ratios of experiencing deprivation according to the different covariates used in the model.

Data showed some missing values. The variables that present missing data are vaccination, height and weight for age, reading activities and playing with toys. Overall, we obtained 7,952 valid cases from 8,216 respondents ( $3 \%$ missing data). Because of these reasons the LCA model showed 45 missing data patterns. Nevertheless, we estimated the model by using the Full Information Maximum Likelihood (FIML), which uses the covariance matrix from the complete data, in order to analyze the missing data for estimating complete data patterns and finally form a generalized covariance matrix (Arburckle, 1996).

\subsection{Goodness-of-Fit Statistics and Selection of Latent Classes}

We have considered five statistics criteria, with the purpose to identify the model with the best goodness of fit and its number of latent classes that will help us to obtain groups of children experiencing multidimensional poverty.

The best-fit model prediction is based upon the following statistics criteria (Collins \& Lanza, 2010):

(1) The Akaike (1987) information criterion (AIC) and the Bayesian information criterion (BIC) (Schwartz, 1978), which are well-known tools for comparing competing models regarding the balance between fit and parsimony. The best-fit model should be identified based on the lowest BIC value.

(2) The entropy value should be near to 1 . This indicates a clear separation of classes.

(3) The homogeneity of classes should include at least $5 \%$ of the total observations.

(4) The probability of belonging to each class must be greater than or equal to 0.85 and.

(5) The last criterion is the Lo-Mendell-Rubin adjusted likelihood ratio test (LMR) and indicates the number of classes that fit the data the best, through showing a significant probability (Lo-Mendell-Rubin et al., 2001). 


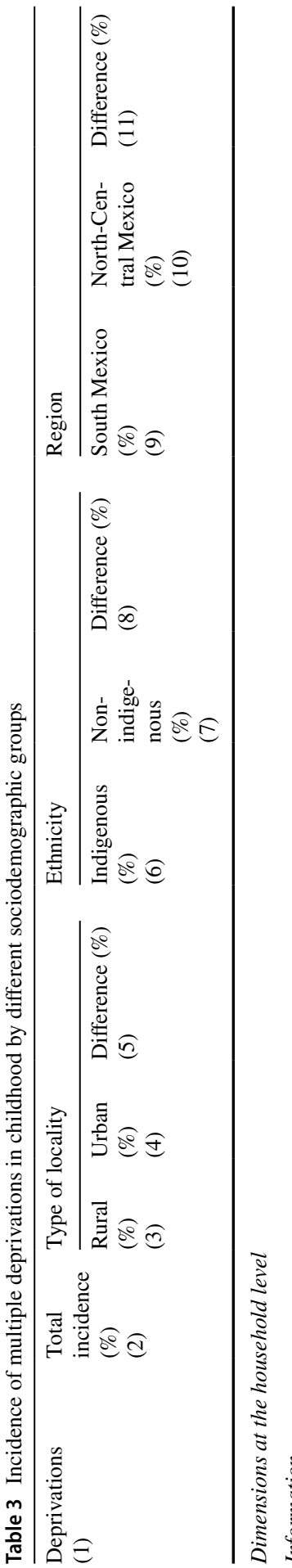

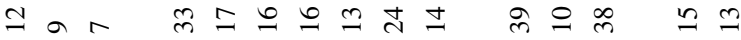

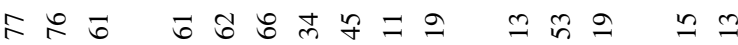

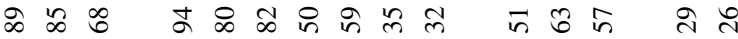

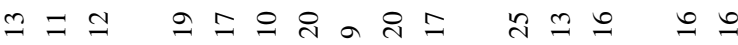

ㅊำ

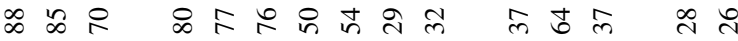

ฟิ

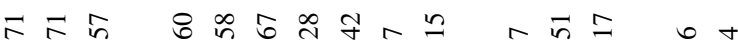

๙ँ ॠ

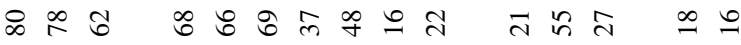

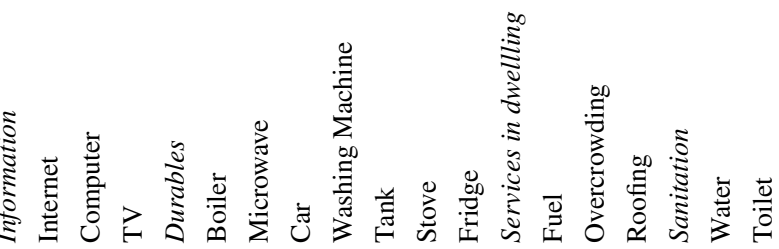




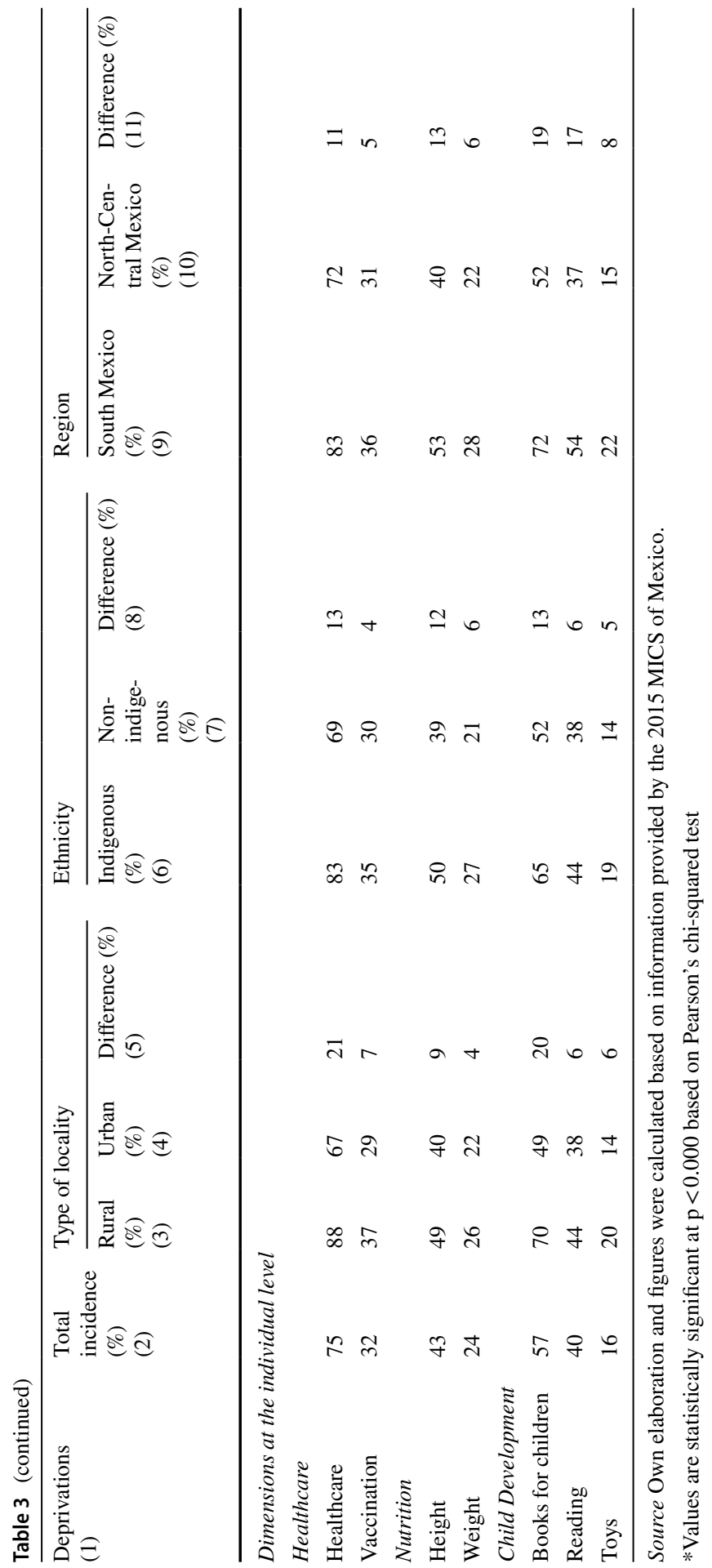




\section{Results}

\subsection{The Extent of Multiple Deprivations in Childhood in Mexico}

We present in this section the descriptive statistics of the incidence of multiple deprivations in childhood in Mexico, by different sociodemographic groups. Table 3 shows the items that children lack at home, as well as the individual needs that have not been satisfied, which are grouped according to the theoretical classification in Table 2. ${ }^{13}$ The results indicate that children in Mexico suffer of different kinds of deprivations; however, the LCA model gives account of the multidimensionally of child poverty in the next section, because it considers these deprivations as a complete view.

Table 3 (column 2) shows that items included in the dimensions of 'information' and 'durables' have the highest incidence of deprivations experienced in childhood. For instance, deprivation due to internet access, computer and TV depict incidences of deprivation of $80 \%, 78 \%$ and $62 \%$. Also, children living in poor households are deprived of access to different durable goods, the highest incidence of these deprivations is due to the lack of a car (69\%); followed by the access to a boiler (68\%), a microwave $(66 \%)$ or a tank at home $(48 \%)$.

On the contrary, the dimension of 'sanitation' shows the deprivations with the lowest incidence rates, the items show an average percentage of 17 . The poverty dimension of 'services in the dwelling' also shows low incidences for the items of fuel (21\%) and roofing (27\%), with the exception of overcrowding, i.e. $55 \%$ of children in Mexico aged 0 to 5 years live in overcrowded households, with three or more persons per room.

There are also several deprivations identified at the individual level, that refer to the non-accomplishment of the specific rights of children. We found that 'healthcare' deprivation in childhood is the highest incidence regarding the child-specific indicators, about $75 \%$ of children in Mexico between 0 and 5 years were not enrolled to a formal health system in 2015 , however, the incidence of deprivation in access to vaccination was lower than healthcare deprivation, of $32 \%$.

Additionally, 'nutrition' is one of the relevant dimensions at the individual level, because it reflects that children have had sufficient and adequate food since they are born. In Mexico, low height for age (-1sd) is still a big problem, $43 \%$ of children are deprived due to this condition and weight for age $(-1 \mathrm{sd})$ presents a lesser deprivation, of $24 \%$.

Also, we may appreciate that the dimension of 'child development' is composed of indicators concerning to the access to information and recreation at home. Then, we found that half of the children in Mexico are deprived due to the lack of children's books at home (57\%) and they are also experiencing deprivation because of the lack of reading at home $(40 \%)$. In contrast, there is a relatively low incidence in deprivation, which is due to the lack of toys and play with parents at home (16\%).

\footnotetext{
13 We do not show the incidences of the dimensions of poverty, since these refer to the latent concept of MCP that encompasses several observed variables, which are the multiple deprivations of childhood.
} 
Table 3 depicts the picture of deprivations presented by poor children in Mexico, through taking into account some of their sociodemographic factors. It is worth mentioning that these indicators will be used as covariates in the CFA model to help predict and characterize MCP.

Overall, children living in the rural context present higher rates of deprivation than those children who live in urban areas. Table 3 (column 5) presents the percentage differences concerning deprivations experienced among children in rural and urban contexts. The highest gaps refer to the lack of fuel, water and toilet at home. These differences are about 40\%age points for the first item and 32 for the second and third items abovementioned.

Also, indigenous children present high incidences regarding deprivations in access to different services, such as internet, computer, TV, boiler, microwave and a car at home, which range between 88 and $70 \%$. Child specific needs for indigenous children present high incidence of deprivations in access to healthcare (83\%), books for children (65\%) and undernutrition by heigh for age (50\%) (column 6). It should be noted that non-indigenous children living in poverty also present high levels of deprivation (column 7); however, there are big disparities between indigenous and non-indigenous children regarding their experience with multiple deprivations, particularly when we talk about the lack of access to a washing machine, a stove and fuel for cooking at home, with $22 \%$ age points of difference on average.

We can appreciate that poor children living in South Mexico present a similar pattern of incidence of deprivation to that of indigenous children, and also experience some disparities compared to poor children living in Central and North Mexico. The first group of children present a very high incidence due to the lack of internet at home $(89 \%)$ and deprivation in access to boiler in the dwelling is the highest for children living in the region of South Mexico (94\%) (column 9). Besides, the incidence of deprivation due to healthcare is also high for indigenous children and those children living in South Mexico (83\%). Also, 63\% of children from South Mexico live in overcrowded households and present the highest incidence of undernutrition, due to low height for age (53\%), in comparison to other groups of children. Child development is also of considerable importance, if we take into account the indicator of availability of books for children, i.e. the incidence of deprivation is $72 \%$.

Furthermore, the highest disparities in the incidence of deprivation between poor children living in South and Central-North Mexico are due to the lack of a boiler, a stove, fuel for cooking at home and the materials of the dwelling. These differences reach a maximum of 39 percentage points among the abovementioned population groups (column 11).

\subsection{Multidimensional Poverty and Latent Class Membership}

Models with one through four latent classes were fit to the data. Table 4 presents the criteria to identify the most adequate number of latent classes, based on the criterion of the best-fit model, explained in the Methods section. We can observe that entropy 
Table 4 Number of latent classes for child multidimensional poverty and statistical tests

\begin{tabular}{llllll}
\hline $\begin{array}{l}\text { Number of } \\
\text { classes }\end{array}$ & $\begin{array}{l}\text { BIC } \\
\text { (Adjusted) }\end{array}$ & Entropy & $\begin{array}{l}\text { Proportion cor- } \\
\text { rectly classified } \\
\text { Min-Max }\end{array}$ & Probability classification & LMR test \\
\hline 1 & $274,026.5$ & & & & $<0.0000$ \\
2 & $172,099.2$ & 0.84 & $41.1 \%-58.9 \%$ & $0.943-0.962$ & $<0.0000$ \\
3 & $166,147.8$ & 0.84 & $19.5 \%-49.8 \%$ & $0.916-0.944$ & $<0.0000$ \\
4 & $164,763.3$ & 0.78 & $14.6 \%-34.0 \%$ & $0.845-0.941$ & 2015 MICS \\
\hline
\end{tabular}

Source Own calculation based on the LCA estimated with information provided by the 2015 MICS survey for Mexico

is of very good quality for two classes and three classes, on average 0.84 , as they show the highest value.

Additionally, BIC tell us that three classes are the most adequate for this model, as this value is lower than the value of two classes. Three classes also show a proportion correctly classify between 19.5 and $49.8 \%$ and there is an adequate probability classification as well. Our statistical analysis tells us that four classes show lesser goodness of fit than the three classes, the entropy was lower than three classes $(0.78$ vs. 0.84). We concluded that the three-class model had the optimal balance of fit and parsimony.

Now we proceed to obtain the average posterior probabilities, with the purpose to know the proportion of children that can be identified in each of the three-latent classes model. Table 5 presents the probabilities of being multidimensionally poor. Children belonging to the first class present the highest probabilities of being multidimensional poor among all types of deprivations, so they are identified as "the extreme poor". The incidence obtained from the estimation of the LCA model reveals that $19.5 \%$ of the children in Mexico belong to this stratum.

Children identified in the second poverty stratum are the moderately poor and the incidence of this group is about $49.8 \%$. This group presents high probabilities in different deprivations, but these are lesser than those presented by the poorest children. The non-poor children were classified in the third latent class and represent $30.7 \%$ of the children population. They show low probabilities of being deprived for the different items presented in Table 5.

We compare the incidence of MCP obtained in this study with those figures presented by CONEVAL (2020). According to CONEVAL (2020), the incidence of children aged less than five years living in moderate poverty is $41.2 \%$ and those children living in extreme poverty is $11.1 \%$. Overall, the incidence of $\mathrm{MCP}^{14}$ according to official figures in Mexico for this age group is $52.3 \% .^{15}$ In contrast, our

\footnotetext{
14 CONEVAL (2019) estimates multidimensional poverty based on the intersection approach of low income and deprivations. However, CONEVAL (2020) does not estimate child poverty based on the children's rights. Child poverty is disaggregated from the figures obtained for the population as a whole.

${ }^{15}$ We can compare our results with 2016 figures of CONEVAL (2020) and the incidence of MCP was $52.4 \%$.
} 
Table 5 Probabilities of being multidimensional poor for children aged less than five years in Mexico, classified by latent classes and multiple deprivations

\begin{tabular}{llll}
\hline Dimensions & Class 1 & Class 2 & Class 3 \\
/ Indicators & (The poorest) & (Moderate & (Non poor) \\
& $(19.5 \%)$ & poor) $(49.8 \%)$ & $(30.7 \%)$ \\
\hline
\end{tabular}

Dimension: Information

Access to internet at home

$\begin{array}{llll}\text { Non-deprivation } & 0.010 & 0.048 & \mathbf{0 . 5 5 3} \\ \begin{array}{l}\text { Deprivation } \\ \text { Computer or laptop }\end{array} & \mathbf{0 . 9 9 0} & \mathbf{0 . 9 5 2} & 0.447 \\ \begin{array}{l}\text { Non-deprivation } \\ \text { Deprivation }\end{array} & 0.025 & 0.071 & \mathbf{0 . 5 6 6} \\ \text { TV contract } & \mathbf{0 . 9 7 5} & \mathbf{0 . 9 2 9} & 0.434 \\ \text { Non-deprivation } & 0.122 & & \\ \text { Deprivation } & \mathbf{0 . 8 7 8} & 0.312 & \mathbf{0 . 6 3 6} \\ & & \mathbf{0 . 6 8 8} & 0.364\end{array}$

Dimension: Durables

Boiler

\begin{tabular}{|c|c|c|c|}
\hline Non-deprivation & 0.014 & 0.190 & 0.697 \\
\hline Deprivation & 0.986 & 0.810 & 0.303 \\
\hline \multicolumn{4}{|l|}{ Microwave } \\
\hline Non-deprivation & 0.035 & 0.218 & 0.713 \\
\hline Deprivation & 0.965 & 0.782 & 0.287 \\
\hline \multicolumn{4}{|l|}{ Vehicle } \\
\hline Non-deprivation & 0.069 & 0.216 & 0.587 \\
\hline Deprivation & 0.931 & 0.784 & 0.413 \\
\hline \multicolumn{4}{|l|}{ Washing machine } \\
\hline Non-deprivation & 0.194 & 0.617 & 0.917 \\
\hline Deprivation & 0.806 & 0.383 & 0.083 \\
\hline \multicolumn{4}{|l|}{ Tank } \\
\hline Non-deprivation & 0.242 & 0.466 & 0.765 \\
\hline Deprivation & 0.758 & 0.534 & 0.235 \\
\hline \multicolumn{4}{|l|}{ Stove } \\
\hline Non-deprivation & 0.302 & 0.960 & 0.993 \\
\hline Deprivation & 0.698 & 0.040 & 0.007 \\
\hline \multicolumn{4}{|l|}{ Fridge } \\
\hline Non-deprivation & 0.392 & 0.812 & 0.983 \\
\hline Deprivation & 0.608 & 0.188 & 0.017 \\
\hline \multicolumn{4}{|c|}{ Dimension: Services in the Dwelling } \\
\hline \multicolumn{4}{|c|}{ Use of fuel for cooking } \\
\hline Non-deprivation & 0.132 & 0.915 & 0.997 \\
\hline Deprivation & 0.868 & 0.085 & 0.003 \\
\hline \multicolumn{4}{|l|}{ Overcrowding } \\
\hline Non-deprivation & 0.219 & 0.364 & 0.702 \\
\hline Deprivation & 0.781 & 0.636 & 0.298 \\
\hline \multicolumn{4}{|l|}{ Roofing materials } \\
\hline Non-deprivation & 0.338 & 0.740 & 0.957 \\
\hline Deprivation & 0.662 & 0.260 & 0.043 \\
\hline
\end{tabular}


Table 5 (continued)

\begin{tabular}{llll}
\hline Dimensions & Class 1 & Class 2 & Class 3 \\
/ Indicators & (The poorest) & (Moderate & (Non poor) \\
& $(19.5 \%)$ & poor) $(49.8 \%)$ & $(30.7 \%)$ \\
\hline
\end{tabular}

Dimension: Sanitation

Water supply at home to drink and use

\begin{tabular}{|c|c|c|c|}
\hline Non-deprivation & 0.414 & 0.887 & 0.976 \\
\hline Deprivation & 0.586 & 0.113 & 0.024 \\
\hline \multicolumn{4}{|c|}{ Toilet at the dwelling } \\
\hline Non-deprivation & 0.456 & 0.907 & 0.980 \\
\hline Deprivation & 0.544 & 0.093 & 0.02 \\
\hline
\end{tabular}

Dimension: Healthcare

Children's access to health

\begin{tabular}{|c|c|c|c|}
\hline Non-deprivation & 0.044 & 0.203 & 0.485 \\
\hline Deprivation & 0.956 & 0.797 & 0.515 \\
\hline \multicolumn{4}{|c|}{ Vaccination (Measles and MMR) } \\
\hline Non-deprivation & 0.601 & 0.695 & 0.712 \\
\hline Deprivation & 0.399 & 0.305 & 0.288 \\
\hline \multicolumn{4}{|c|}{ Dimension: Nutrition } \\
\hline \multicolumn{4}{|c|}{ Height for age } \\
\hline Non-deprivation & 0.342 & 0.587 & 0.693 \\
\hline Deprivation & 0.658 & 0.413 & 0.307 \\
\hline \multicolumn{4}{|l|}{ Weight for age } \\
\hline Non-deprivation & 0.619 & 0.780 & 0.834 \\
\hline Deprivation & 0.381 & 0.220 & 0.166 \\
\hline \multicolumn{4}{|c|}{ Dimension: Child Development } \\
\hline \multicolumn{4}{|c|}{ Books for children (2 or more) } \\
\hline Non-deprivation & 0.182 & 0.386 & 0.667 \\
\hline Deprivation & 0.818 & 0.614 & 0.333 \\
\hline \multicolumn{4}{|c|}{ Parents read a book for the child } \\
\hline Non-deprivation & 0.436 & 0.585 & 0.708 \\
\hline Deprivation & 0.564 & 0.415 & 0.292 \\
\hline \multicolumn{4}{|c|}{ Children have toys at home and play with parents } \\
\hline Non-deprivation & 0.745 & 0.840 & 0.901 \\
\hline Deprivation & 0.255 & 0.160 & 0.099 \\
\hline
\end{tabular}

Source Own elaboration based on the 2015 MICS survey for Mexico.

Note Probabilities highlighted in bold are the highest for each item.

study reveals that the incidence of MCP is $69.3 \%$ with the sum of the two poverty groups. This last result is more similar than the index of deprivation, presented by CONEVAL, who shows an incidence rate of $76.5 \%$ for children presenting at least one deprivation, although CONEVAL considers deprivations at the household level.

Moreover, the access to 'information' is also analyzed as a poverty dimension, which includes different indicators: deprivations in access to internet, computer 
or laptop and TV in the dwelling, and shows probabilities near to one for the poorest children, much higher than the probabilities of the non-poor children.

Nevertheless, deprivation in access to internet at home is the highest probability (0.99) shown between and within classes, i.e. children living in moderate poverty and non-poverty present high probabilities as well.

On the other hand, the set of deprivations encompassing the dimension of 'durables' in the dwelling: boiler, microwave, vehicles, wash machine, tank, stove and fridge show high probabilities for children belonging to the poorest stratum (higher than 0.60). Similarly, there are high probabilities experienced by the moderately poor children, regarding the availability of boiler, microwave and vehicles in the household, but they show lower risks to experiencing deprivation in the access to stove and fridge, with almost null probabilities. And the nonpoor children show low or null probabilities of presenting deprivation in access to durables.

Additionally, if we consider the poverty dimension of 'services in the dwelling', we can also appreciate that fuel for cooking at home, overcrowding and roofing materials are commonly deprivations for the poorest children, who show probabilities above 0.66 for these items. On the contrary, children experiencing moderate poverty show low probabilities in the items abovementioned, although they present a considerable probability of deprivation due to overcrowding, of 0.64.

Also, the poorest children in Mexico show relatively high probabilities of deprivation due to 'sanitation'. The probabilities for children lacking water supply at home are 0.59 and 0.54 due to the lack of a toilet in the dwelling. These probabilities are drastically reduced for children living in moderate poverty and are close to zero for the non-poor children.

Now, we will analyze the poverty dimensions by considering 'child-specific indicators'. We found that children living in the poorest stratum of poverty are very likely to experience deprivation in access to healthcare, this probability is 0.96 , which is as high as the probability presented in deprivation due to access to information. On the contrary, probabilities for children of being deprived of vaccination are less than 0.40 on average, for the three poverty groups.

Besides, 'nutrition' is one aspect directly related to the children's health and growth. When a child is deprived of adequate and sufficient nutrition; then they can present different types of malnutrition. In Mexico, the poorest children have a high probability of low height for age (stunting), of 0.66 .

We also highlight that there is a high probability of deprivation due to the lack of availability of books for children at home, depicted by children experiencing extreme poverty. The most severe deprivation in this domain represents a probability of 0.82 for the poorest children, and children belonging to the moderate poverty group is 0.61 .

Moreover, children living in multidimensional poverty present considerable probabilities of deprivation regarding to 'child development', when parents lack time to read a book (stories) with their children. High probabilities occur for children belonging to the poorest group and are about 0.56 . However, children belonging to the poorest stratum do not present high risks regarding deprivation in access to toys and play with parents $(0.26)$. 
According to Collins and Lanza (2010) a latent class $c$ is highly homogeneous when members of $c$ are likely to present the same observed response pattern. This also entails that one response pattern is highly characteristic of the latent class $c$. Thus, in this analysis we can observe a high level of homogeneity associated to the latent classes estimated in the conditional LCA, because there are specific response patterns shown in Appendix 1. For example, the response pattern of the first latent class is characterized by the highest level of deprivation comparing with the other two classes in each poverty dimension, i.e. there is homogeneity. So, we present Appendix 1, composed of Figs. 1.1 to 1.7, which show the item-response probabilities for a three-latent-class model, with the aim to illustrate homogeneity and latent class separation by poverty dimensions, which also encompass types of deprivation, such as deprivation in the access to information, durables, services in the dwelling, sanitation, healthcare, nutrition, and child development.

Homogeneity is also shown for the two other latent classes. Children in the second latent class are very likely to show lower probabilities of presenting poverty than those children classified in the first latent class, for all deprivations. However, they never present lesser probabilities of poverty than children classified in the third latent class (the non-poor children).

Moreover, we can observe a high degree of latent class separation, because there is a response pattern with a large rate of the occurrence conditional probability on one latent class and a small rate of the occurrence conditional probability on any of the other latent classes (Collins and Lanza, 2010). Also, class two, which represents the moderately poor, clearly presents an intermediate level between the highest probabilities that children present in class one and the lowest probabilities of children in class three. So, the third class which represents the non-poor children shows the lowest level of probability of presenting poverty and deprivation (for instance, deprivation in access to sanitation, Appendix 1.4).

\subsection{Determinants of Multidimensional Child Poverty}

We pose that poverty is multifactorial and we make use of covariates to estimate a conditional LCA. Covariates that were significant in the model are shown in Table 6: Children classified in the first latent class of poverty ("the poorest children") present the highest odds ratios of experiencing multiple deprivations, in comparison to the latent class three (the reference group), i.e. the children who are not poor. The sociodemographic determinants allude to children living in rural areas and children settle down in the South region of Mexico. These covariates give account of very high disparities in the whole country. ${ }^{16}$ The odds ratios are 26 and 13 for children belonging to the first stratum and who present these conditions.

\footnotetext{
16 We also consider income deciles provided in the MICS survey, but this variable was not significant.
} 
Table 6 Covariates and odd ratios by categorical latent classes (the reference group is Class 3)

Covariates

(deprivation category is shown)
OR

\section{Class 1 on}

Type of locality: Rural

$26.3 *$

Region: South Mexico

$12.9^{*}$

Father's educational attainment: below mandatory education

Mother's educational attainment: below mandatory education

Ethnicity: Indigenous

Children aged 0-2 years

Mother's age (less than 18 years old)

Class 2 on

Type of locality: Rural

Region: South Mexico

Fathers's educational attainment: below mandatory education

Mother's educational attainment: Low level

Ethnicity: Indigenous

Children aged 0-2 years

Mother's age (less than 18 years old)

Source Own elaboration based upon the LCA estimated with the 2015 MICS data survey for Mexico

*Values are statistically significant at $\mathrm{p}<0.001$

We also obtained high risks of sinking into MCP when the father or mother present a low educational attainment, i.e. below mandatory education ${ }^{17}$; or when children are indigenous; comparing to those children who belong to the third latent class. We obtained six odds ratios on average for the poorest children presenting these determinants.

This study also reveals that children with a young mother are more likely of presenting multidimensional poverty, because odds ratios are slightly greater than the unit for the poorest children. Also, children are at higher risk when they are zero to two years old, comparing to the non-poor children of the same age.

We can also compare the odds ratios presented by the moderately poor (the second latent class) and we observe that probabilities of being poor are not as high as the ones presented by the poorest children. However, some factors have more influence, such as for children living in rural areas, as well as for the children living in the South region of Mexico; plus the low educational attainment of parents. Besides, young mothers aged less than eighteen years is a factor with higher odds ratios for children belonging to moderate poverty than for children in the extreme poverty group, comparing to the reference latent class.

\footnotetext{
17 According to the Mexican Constitution, the mandatory education in Mexico should be accomplished when the person completes high school education (DOF, 1917, reformed in 2012).
} 


\section{Discussion}

We have corroborated empirically that poverty is not only multidimensional but multifactorial as well. MCP comprises deprivations of the rights of children, however, there are socio-economic or demographic conditions that influence the probabilities of experiencing extreme or moderate poverty. Thus, we estimated a conditional LCA model to obtain three poverty latent classes, which are extreme and moderate poverty and no poverty. We found homogeneity patterns showing us that the first latent class presents the highest probabilities of deprivation for various poverty dimensions; so, we have identified this class as "the poorest stratum". On the contrary children living in moderate poverty present lower risks of sinking into poverty than those children experiencing extreme poverty.

Overall, $69.3 \%$ of the Mexican children are living in multidimensional poverty, i.e., they present multiple deprivations. The poorest children represent $19.5 \%$ and children living in moderate poverty represent $49.8 \%$, both add up to the incidence of multidimensional poverty. Children experiencing MCP present the highest probabilities because of deprivations in access to information, such as the internet at home; computer or laptop; TV contract; as well as different durables at home, such as a boiler, a microwave or a vehicle, and concerning child development, children have high probabilities of lacking books at home. Also, there are high probabilities of presenting deprivations because of the lack to healthcare access in childhood plus poor housing conditions, such as living in overcrowded households.

Deprivation in access to internet at home and the access to a computer depict the highest probabilities of deprivation for both poverty strata. This can be explained because of the large digital gap in Mexico, concerning the access and use of Information and Communication Technologies (ICT), since it is now a form of social inequality, i.e. a little more than half of Mexican households do not have internet connection and only $45.6 \%$ have a computer (MartínezDomínguez, 2018).

Moreover, we found that children who belong to the group of moderate poverty and those who are not poor present high probabilities of deprivation in access to a health institution, more than 0.5 . This is explained because the health system in Mexico has not been universal, on the contrary, it has been exclusive because the access is for people that are contributing through formal employments (BarbaSolano, 2004).

Also, chronic malnutrition is a recurrent problem in the poorest population groups, the probability is about 0.66 . It is also a big problem in rural areas, for indigenous children and children living in the South region of Mexico, as we found that the incidence is on average $50 \%$. Chronic malnutrition or stunting is considered a long-term developed deficiency and may cause irreversible damage to brain development, preventing children from fully developing their physical and cognitive 
potential (Sudfeld et al, 2015). It is urgent to include well-being policies concerning the actions of proven effectiveness for the prevention of malnutrition in Mexico, from gestation to five years of life (Cuevas-Nasu et al, 2019).

One of the contributions of this research paper has been the inclusion of 'child development' as one of the dimensions to measure MCP in Mexico. Early childhood development is a process that includes physical, language, motor, cognitive, and socio-emotional development and occurs in the first years of life. So, the lack of early education can have irreversible consequences for the rest of the children's life (UNICEF, 2018). The probabilities for children living in multidimensional poverty regarding the lack of books at home are higher than 0.72 on average. Reading children's books and storytelling with children promotes brain development and imagination, as well as permits the language development and strengthens their emotions and motor skills (Fritjers et al, 2000; Hume et al, 2015). The probabilities of children living in extreme poverty, regarding deprivation due to the lack of reading books at home are slightly higher than 0.5 . So, it is also important to create activities for children as well as to play with them.

We should not underestimate the role of parents to allow child development, for example, through using toys, whether homemade, invented or purchased (Bundy et al, 2009). Child development is crucial during the first five years of life, as $90 \%$ of the brain develops during this time. There are risk factors, such as poverty, malnutrition, health problems and not very stimulating environments, which are associated with delays in cognitive, motor and social-emotional development (O'Shea-Cuevas et al., 2015).

Additionally, we add the sociodemographic determinants which are treated as 'covariates' in the model. These variables reveal the risks (odds ratios) of experiencing MCP in Mexico. Children living in rural areas are very likely to present deprivations of many types; as well as children living in the South of Mexico. The ethnicity is also important, as indigenous children are particularly vulnerable to sink into poverty. The odds ratios are particularly high for the latent class of children living in extreme poverty. Children living in rural areas as well as those who belong to indigenous population groups have been historically excluded from the social development and wealth in Mexico (CONEVAL, 2018). More than half of the people in extreme poverty live in rural settings (CONEVAL, 2020).

Thus, children who live in an indigenous or rural place are more likely to experience multidimensional poverty, one of the explanations is because the gap in poverty reduction has widened in the last ten years, i.e. poverty has increased for indigenous children, while poverty has decreased for non-indigenous children. The region where children live is also a determinant factor, Chiapas is a state of the South Mexican region and concentrates a large part of indigenous preschool and primary schools, these children have a high probability of presenting MCP (UNICEF, 2020; UNICEF \& CONEVAL, 2019). 
Furthermore, children with parents presenting a low educational attainment are also at a higher risk of experiencing MCP. In Mexico, the indigenous population shows the highest risk for not going to school, not completing compulsory basic education or not achieving the expected levels of learning. The reasons are diverse, but the high degree of marginalization of many indigenous communities and the lack of access to schools, or the precarious conditions are among the main causes (UNICEF, 2018).

\section{Conclusion}

The LGDNNA establishes that every child is entitled to all rights that have been defined in the Mexican normative frameworks. The Mexican Constitution and the LGDNNA mandate that the Mexican State should ensure the "best interest" principle for children, regarding child protection. Also, the policy-making process or governmental interventions should be implemented in terms of the principle of progressivity of rights, which implies that rights may increase, but not decrease. The framework of child rights implies the access to public services provided by the State, as well as the right to participate as full members of the society. Then, child-specific rights should be included into the measurement of MCP, to inform social policy accurately.

To sum up, our analysis indicates that there are several risk factors that determine MCP and the exposure of children to multiple deprivation. For instance, the lack of access to effective insurance mechanisms and strategies for dealing with socioeconomic crisis have put children into vulnerability, such as for example the Covid-19 pandemic, with low percentage of families and children accessing to healthcare.

Consequently, the State should implement both universal and targeted policies to eradicate MCP as well as to eliminate extreme poverty. It is also necessary that the State complies with the provision of public services associated with the rights of the children through universal policies, which shall be implemented considering not only the multiple deprivations experienced in childhood, but also by considering the factors of greater risks that determine multidimensional poverty.

\section{Appendix}

1. Item-Response Probabilities for a Three-Latent-Class Model with homogeneity and latent class separation, by poverty dimensions 
1.1. Deprivation in access to Information

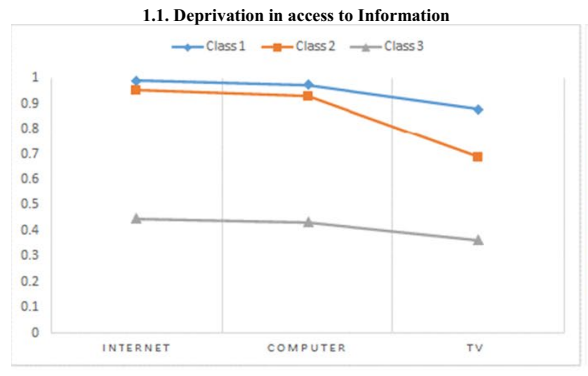

1.3. Deprivation in access to services in the dwelling

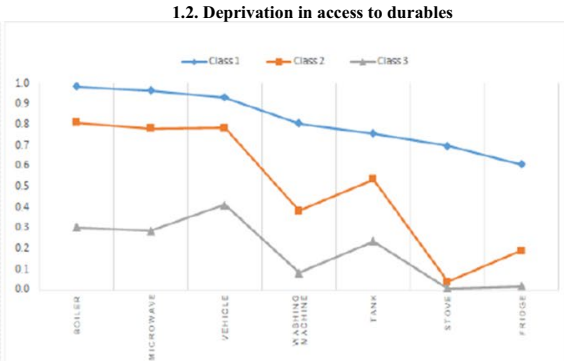

1.4. Deprivation in access to sanitation
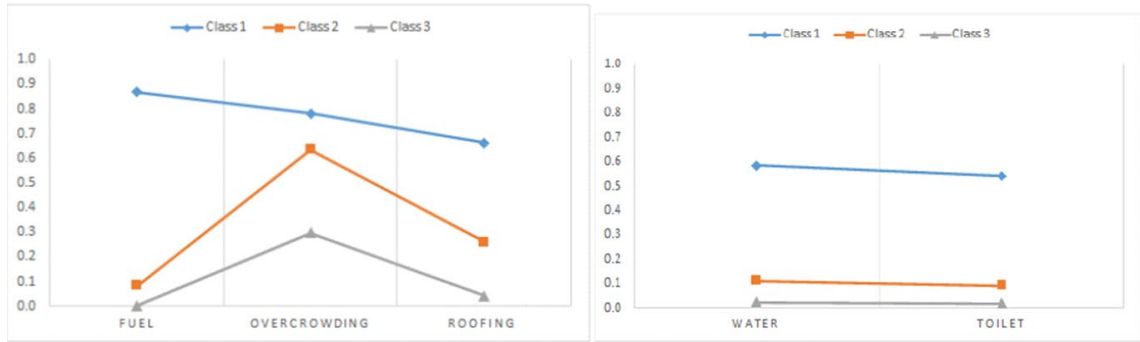

1.5. Deprivation in access to healthcare

1.6. Deprivation due to nutrition

$\rightarrow$ Class $1 \rightarrow$ Class $2 \rightarrow$ Class

$\multimap$ Class $1 \multimap$ Class $2 \ldots$ Class 3

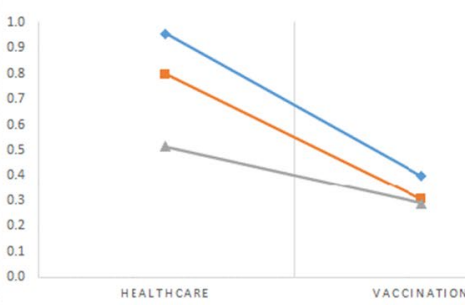

1.7. Deprivation in access to child developmen
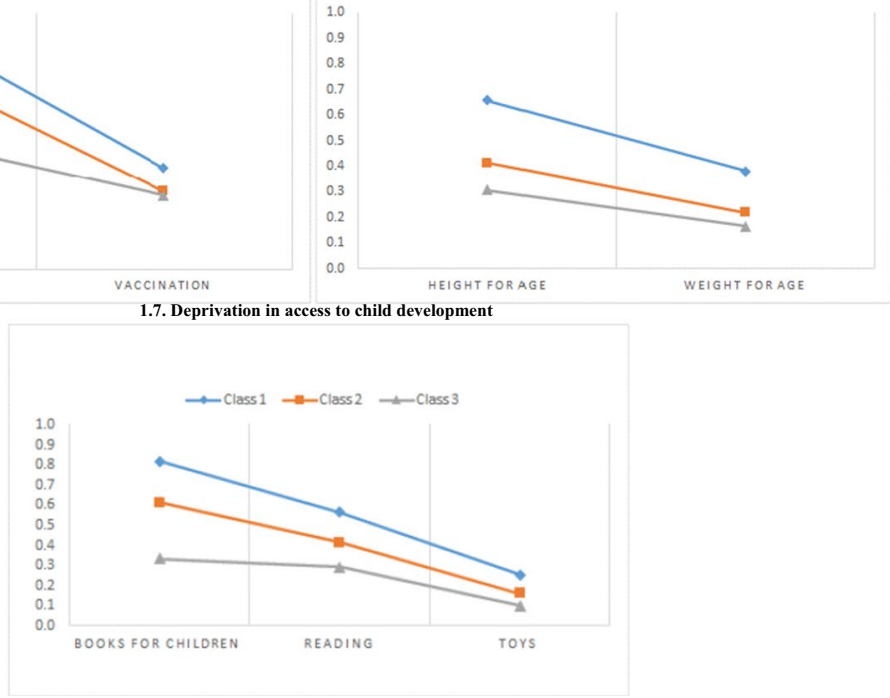
Acknowledgements The corresponding author acknowledges the fellowship and academic supervision received from "UNAM. Posdoctoral Fellowship Program (Programa de Becas Posdoctorales) at the Universidad Nacional Autónoma de México (UNAM) as Fellow of the Programa Universitario de Estudios del Desarrollo (PUED), advised by Dr Delfino Vargas Chanes".

Funding The corresponding author thanks the funding received from the Postdoctoral Fellowship Program at UNAM, 2019 Call.

\section{References}

Akaike, H. (1987). Factor analysis and AIC. Psychometrika, 52, 317-332. https://doi.org/10.1007/ BF02294359

Arbuckle, J. L. (1996). Full information estimation in the presence of incomplete data. In G. A. Marcoulides \& R. E. Schumacker (Eds.), Advanced structural equation modeling (pp. 243-277). Lawrence Erlbaum.

Barba-Solano, C. (2004). Régimen de Bienestar y Reforma Social en México. Serie Políticas Sociales, Santiago De Chile: Naciones Unidas y CEPAL, 92, 1-56.

Ben-Arieh, A., Casas, F., Frønes, I., \& Korbin, J. E. (2014). Handbook of child well-being theories, methods and policies in global perspective. Dordrecht: Springer.

Berlinski, S., \& Schady, N. (2015). Los primeros años. El bienestar infantil y el papel de las políticas públicas. Banco Interamericano de Desarrollo.

Biggeri, M., \& Cuesta, J. A. (2021). An integrated framework for child poverty and well-being measurement: Reconciling theories. Child Indicators Research, 14, 821-846. https://doi.org/10.1007/ s12187-020-09774-0

Biggeri, M., J.F. Trani \& V. Mauro. (2010). The multidimensionality of child poverty: An empirical investigation on children of Afghanistan. OPHI Research in Progress, 19.

Bolboacă, S. D., Jäntschi, L., Sestraş, A. F., Sestraş, R. E., \& Pamfil, D. C. (2011). Pearson-Fisher chi-square statistic revisited. Information, 2(3), 528-545. https://doi.org/10.3390/info2030528

Bronfenbrenner, U. (1981). The ecology of human development. Harvard University Press.

Bundy, A. C., Luckett, T., Tranter, P. J., Naughton, G. A., Wyver, S. R., Ragen, J., \& Spies, G. (2009). The risk is that there is 'no risk': A simple, innovative intervention to increase children's activity levels. International Journal of Early Years Education, 17(1), 33-45. https://doi.org/10.1080/ 09669760802699878

Collins, L. M., \& Lanza, T. (2010). Latent class and latent transition analysis: With applications in the social, behavioral, and health sciences. Wiley.

CONEVAL (Consejo Nacional de Evaluación de la Política de Desarrollo Social). (2010). Methodology for multidimensional poverty measurement in Mexico. Retrieved July 10, 2020 from https:// www.coneval.org.mx/rw/resource/coneval/med_pobreza/MPMMPingles100903.pdf

CONEVAL (Consejo Nacional de Evaluación de la Política de Desarrollo Social). (2018). Informe de Evaluación de la Política de Desarrollo Social 2018, Ciudad de México: CONEVAL 2018. Retrieved July 9, 2020 from https://www.coneval.org.mx/Evaluacion/IEPSM/IEPSM/Docum ents/IEPDS_2018.pdf

CONEVAL (Consejo Nacional de Evaluación de la Política de Desarrollo Social). (2019). Metodología para la Medición Multidimensional de la Pobreza en México, Ciudad de México: Coneval, Tercera edición.

CONEVAL (Consejo Nacional de Evaluación de la Política de Desarrollo Social). (2020). Medición de la Pobreza. Programas de Cálculo y Bases de Datos 2008, 2010, 2012, 2016 y 2018. Retrieved July 11, 2020 from https://www.coneval.org.mx/Medicion/MP/Paginas/Programas_BD_08_10_ 12_14_16_18.aspx

Cuesta, J., Biggeri, M., Hernandez-Licona, G., Aparicio, R., \& Guillén-Fernández, Y. (2020). The political economy of multidimensional child poverty measurement: A comparative analysis of Mexico and Uganda. Oxford Development Studies, 48(2), 117-134. https://doi.org/10.1080/ 13600818.2020.1739261

Cuevas-Nasu, L., Gaona-Pineda, E. B., Rodríguez-Ramírez, S., Morales-Ruán, M. C., González-Castell, L. D., García-Feregrino, R., Gómez-Acosta, L. M., Ávila-Arcos, M. A., Shamah-Levy, T., 
\& Rivera-Dommarco, J. (2019). Desnutrición crónica en población infantil de localidades con menos de 100000 habitantes en México. Salud Pública De México, 61(6), 833-840.

Diario Oficial de la Federación (DOF). (1917). Constitución Política de los Estados Unidos Mexicanos, Last reform published on 08-05-2020, Ciudad de México: Cámara de Diputados del H. Congreso de la Unión. Retrieved August 6, 2020 from http://www.diputados.gob.mx/LeyesBiblio/pdf_mov/Constitucion_Politica.pdf

Diario Oficial de la Federación (DOF). (2004). Ley General de Desarrollo Social, Last reform published on 25-06-2018. Ciudad de México: Cámara de Diputados del H. Congreso de la Unión. Retrieved July 10, 2020 from http://www.diputados.gob.mx/LeyesBiblio/pdf/264_250618.pdf.

Diario Oficial de la Federación (DOF). (2014). Ley General de los Derechos de Niñas, Niños y Adolescentes, Last reform published on 17-10-2019, Ciudad de México: Cámara de Diputados del H. Congreso de la Unión. Retrieved August 6, 2020 from http://www.diputados.gob.mx/LeyesBiblio/ pdf/LGDNNA_171019.pdf

Donald, A., \& Mottershaw, E. (2009). Poverty, inequality and human rights: Do rights make a difference? New York: Joseph Rowntree Foundation.

Duncan, G. J., \& Brooks-Gun, J. (2003). Family poverty, welfare reform and child development. Child Development, 71(1), 188-196. https://doi.org/10.1111/1467-8624.00133

Espíndola, E., G. Sunkel G., Murden A. \& Milosavljevic. V. (2017). Medición multidimensional de la pobreza infantil. Una revisión de sus principales componentes teóricos, metodológicos y estadísticos, Santiago: Naciones Unidas and CEPAL.

Fritjers, J. C., Barron, R. W., \& Brunello, M. (2000). Direct and mediated influences of home literacy and literacy interest on prereaders' oral vocabulary and early written language skill. Journal of Educational Psychology, 92(3), 466-477.

Garbarino, J. (2014). Ecological perspective on child well-being. In A. Ben-Arieh, F. Casas, I. Frønes, \& J. E. Korbin (Eds.), Handbook of child wellbeing (pp. 1365-1384). Springer.

Gordon, D. Nandy, S., Pantazis, C., Pemberton, S. \& Townsend, P. (2003). Child Poverty in the Developing World, Bristol: The Policy Press. Retrieved October 25, 2020 from https://www.unicef.org/socia lpolicy/files/child_poverty_in_the_developing_world.pdf

Gordon, D., \& Nandy, S. (2012). Measuring child poverty and deprivation. In A. Minujín \& S. Nandy (Eds.), Global child poverty and wellbeing. Measurement, concepts, policy and action (pp. 57-102). Bristol: The Policy Press.

Henry, N. W. (2014). Latent structure analysis. Wiley StatsRef: Statistics Reference Online. https://doi. org/10.1002/9781118445112.stat02466

Hume, L. E., Lonigan, C. J., \& McQueen, J. D. (2015). Children's literacy interest and its relation to parents' literacy-promoting practices. Journal of Research in Reading, 38(2), 172-193. https://doi.org/ 10.1111/j.1467-9817.2012.01548.x

INSP (Instituto Nacional de Salud Pública) \& UNICEF (The United Nations Children's Fund). (2016). Encuesta Nacional de Niños, Niñas y Mujeres, 2015, Resultados Principales. Retrieved September 1, 2019 from http://mics.unicef.org/surveys

Lo, Y., Mendell, N. R., \& Rubin, D. B. (2001). Testing the number of components in a normal mixture. Biométrika, 88(3), 767-778. https://doi.org/10.1093/biomet/88.3.767

Martínez Domínguez, M. (2018). Acceso y uso de tecnologías de la información y comunicación en México: factores determinantes. PAAKAT: Revista De Tecnología y Sociedad. https://doi.org/10. 32870/pk.a8n14.316

Gabriel, O.-C., Antonio, R.-C., Daniel, A.-V., Manuel, V.-M., Joaquín, C.-M., Elizabeth, H.-C., et al. (2015). Sistema de Protección Social en Salud para la detección y atención oportuna de problemas del desarrollo infantil en México. Boletín Médico Del Hospital Infantil De México, 72(6), 429-437. https://doi.org/10.1016/j.bmhimx.2015.10.002

Pomati, M., \& Nandy, S. (2019). Assessing progress towards SDG2: Trends and patterns of multiple malnutrition in young children under 5 in West and Central Africa. Child Indicators Research, 13, 1847-1873. https://doi.org/10.1007/s12187-019-09671-1

Save the Children. (2008). The Child Development Index: Holding governments to account for children's wellbeing. Save the Children.

Serrano, S. \& Vázquez, D. (2013). Los Derechos en Acción. Obligaciones y Principios de Derechos Humanos, México: FLACSO.

Schotte, S., Zizzamia, R., \& Leibbrandt, M. (2018). A poverty dynamics approach to social stratification: The South African case. World Development, 110, 88-103. https://doi.org/10.1016/j.worlddev.2018. 05.024 
Schwartz, G. (1978). Estimating the dimension of a model. The Annals of Statistics, 6(2), 461-464. https://doi.org/10.1214/aos/1176344136

Sudfeld, C. R., McCoy, D. C., Danaei, G., Fink, G., Ezzati, M., Andrews, K. G., \& Fawzi, W. W. (2015). Linear growth and child development in low- and middle-income countries: A meta-analysis. Pediatrics, 135(5), 1266-1275. https://doi.org/10.1542/peds.2014-3111

Speth, J. G. (1998). Poverty: A denial of human rights. Journal of International Affairs, 52(1), $277-292$.

Townsend, P. (1979). Poverty in the United Kingdom: A survey of household resources and standards of living. Penguin Books.

Townsend, P. (2008). The abolition of child poverty and the right to social security: A possible UN model for child benefit? LSE-University of Bristol.

Tuñón, I., S. Poy y A. Coll. (2015). Pobreza infantil en las ciudades de la Argentina 2010-2014: Diferentes mediciones de la pobreza infantil y una propuesta multidimensional desde un enfoque de derechos. Edición especial - Ciudad Autónoma de Buenos Aires: Educa.

United Nations. (1990). Convention on the Rights of the Child, United Nations General Assembly, entry into force 2 September 1990. Retrieved April 30, 2019 from https://www.ohchr.org/Documents/ ProfessionalInterest/crc.pdf

United Nations. (1995). The Copenhagen Declaration and Programme of Action, World Summit for Social Development, 6-12 March 1995, New York: United Nations. Retrieved October 25, 2020 from https://www.un.org/esa/socdev/wssd/text-version/index.html

United Nations General Assembly (UNGA). (2006). Promotion and Protection of the Rights of Children: Report of the third committee. United Nations.

United Nations Economic Commission for Europe (UNECE) (2020). Poverty Measurement: Guide to Data Disaggregation. Conference of European Statisticians, Sixty-eighth plenary session. Geneva: UNECE. Retrieved July 11, 2020, from http://www.unece.org/fileadmin/DAM/stats/documents/ece/ ces/2020/09Rev1_Poverty_Measurement_Guide_after_consultation.pdf.

UNICEF (The United Nations Children's Fund). (2004). The State of the World's Children 2005: Childhood under Threat. UNICEF.

UNICEF (The United Nations Children's Fund). (2010). Child poverty: A priority challenge. Challenges, Newsletter on Progress towards the Millennium Development Goals from a Child Rights Perspective, United Nations and ECLAC, 10, 12.

UNICEF (The United Nations Children's Fund). (2018). Informe Anual, México 2018, Ciudad de México: UNICEF.

UNICEF \& CONEVAL. (2019). Pobreza infantil y adolescente en México 2008-2016, Ciudad de México: UNICEF.

UNICEF. (2020). Informe Anual, México 2019, Ciudad de México: UNICEF.

Vermunt, J. K., \& Magidson, J. (2020). How to perform three-step latent class analysis in the presence of measurement non-invariance or differential item functioning. Structural Equation Modeling: A Multidisciplinary Journal. https://doi.org/10.1080/10705511.2020.1818084

Wagmiller, R. L., \& Adelman, R. M. (2009). Childhood and intergenerational poverty. The long-term consequences of growing up poor, reports, Columbia. Academic Commons. https://doi.org/10.7916/ D8MP5C0Z

Wang, J., \& Wang, X. (2012). Structural equation modeling. Wiley.

WHO (World Health Organization). (2010). Country profile indicators. WHO.

Publisher's Note Springer Nature remains neutral with regard to jurisdictional claims in published maps and institutional affiliations. 